\title{
АНАЛИЗ СОСТОЯНИЯ БАНКОВСКОЙ СИСТЕМЫ РФ В 2018-2020 ГГ.
}

\author{
(c) 2021 Тадтаева Валида Валерьевна \\ кандидат экономических наук \\ Финансовый университет при Правительстве Российской Федерации, \\ Владикавказский филиал, Россия, Владикавказ \\ E-mail:VVTadtaeva@fa.ru \\ (c) 2021 Мамсурова Фиалета Хазбиевна \\ старший преподаватель кафедры прикладной математики \\ Северо-Осетинский государственный университет имени К. Л. Хетагурова, Россия, Владикавказ \\ E-mail: fioleta1@mail.ru \\ (c) 2021 Кумаритова Зарина Батыровна \\ студентка 3 курса \\ Финансовый университет при Правительстве Российской Федерации, \\ Владикавказский филиал, Россия, Владикавказ \\ E-mail: zarina.kumaritova73@gmail.com
}

Данная статья является результатом проведенного анализа банковского сектора России в 20182020 гг. При проведении анализа была определена роль, которую играет ЦБ РФ в сфере регулирования и контроля банковской системы, в частности, при повышении ее надежности. Для этого были подробно изучены три этапа банковского надзора, осуществляемого Банком России. На основе полученных данных были сделаны соответствующие выводы.

Ключевые слова: Банк России, банковский надзор, банковский сектор, лицензия, банкротство.

Центральный банк Российской Федерации осуществляет банковский надзор за деятельностью кредитных организаций. Система надзора ориентирована на достижение трёх основных целей:

1. Обеспечение денежной и финансовой стабильности, т.е. недопущение банкротства банков и принятие мер по их оздоровлению;

2. Обеспечение эффективности банковской системы за счет повышения качества активов и уменьшения потенциальных рисков.

3. Защита интересов вкладчиков.

Банковский надзор проводится в 3 этапа:

1. Лицензирование;

2. Дистанционный (документарный) надзор;

3. Инспектирование на местах.
Центральный банк Российской Федерации принимает решение о регистрации кредитных организаций, обладает исключительным правом выдачи, приостановления и отзыва лицензий, предоставляемых КО.

По состоянию на 1 января 2020 года в России насчитывалось 836 зарегистрированных кредитных организаций, тогда как из них реально действующими (имеющими лицензию на осуществление банковских операций) были всего лишь 442. Уже из этих данных можно сделать вывод о низкой эффективности банковской системы РФ.

Из 442 кредитных организаций, имеющих лицензию, 402 являлись банками, а 40 - небанковскими кредитными организациями (Рис. 1).

С 2017 года кредитные организации, в зави-

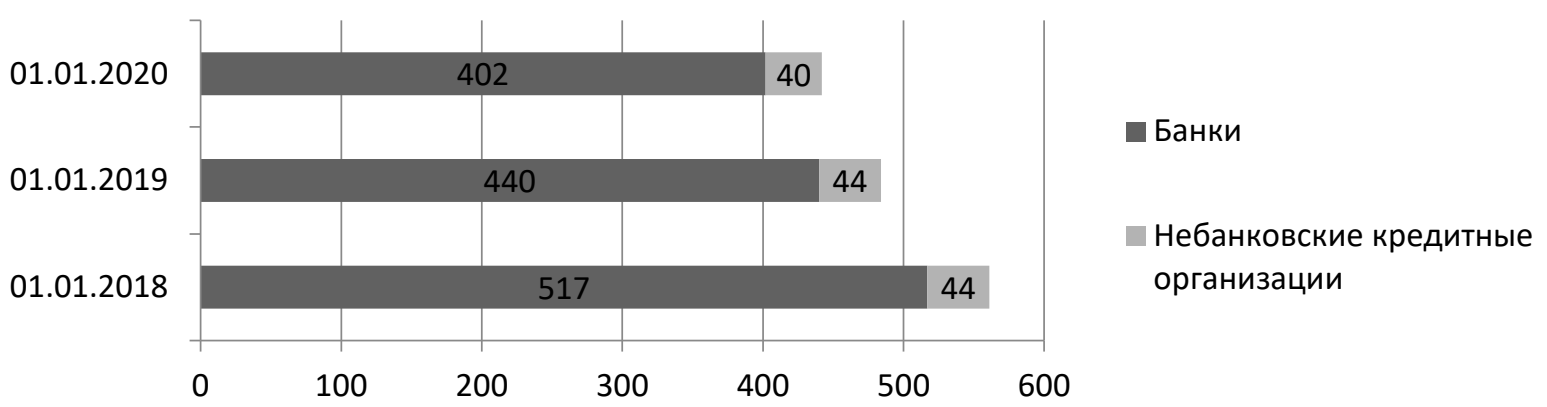

Рuc. 1. Структура действующих КО в 2018-2020 гг. (в ед.) [3] 
симости от уровня капитала, объема требований, предъявляемых к ним Центральным Банком, и полномочий, стали подразделяться на 2 группы: банки с базовой лицензией и банки с универсальной лицензией (Таблица 1).

Однако, надо отметить, что фактический раздел банков на типы в соответствии с лицензией произошел только с 1 января 2018 года, до этого момента (а именно, в период с вступления в силу Федерального закона «О внесении изменений в отдельные законодательные акты Российской Федерации» от 01.05.2017 г. № $92-$ Ф3 до 01.01.2018 г.) все банки были признаны банками с универсальной лицензией при наличии у них обязательства за указанный период увеличить свой уставной капитал до суммы, достаточной для универсальной лицензии, либо получить базовую лицензию или вовсе изменить свой статус.

Исходя из характеристик и отличительных признаков, рассмотренных в Таблице 1 можно сделать вывод о том, что банки с базовой лицензией теряют свою инвестиционную привлекательность рядом с банками с универсальной лицензией. Им становится труднее находить капитал, поскольку люди охотнее вкладывают деньги в банки с крупным капиталом, считая, что так надежнее (чем больше капитал, тем меньше вероятность того, что банк обанкротится и не сможет рассчитаться по своим обязательствам).
В результате это сказывается на стабильной деятельности маленьких банков, т.е. появляется угроза их банкротства.

На 1 января 2020 года, среди 402 банков, 266 банков были с универсальной лицензией (на 25 меньше, чем в 2019 году), а 136 (на 13 меньше, чем в 2019 году) - с базовой (Рис. 2).

С одной стороны, количественное преимущество банков с универсальной лицензией положительное явление (у них больше капитал, соответственно, они надежнее), но, с другой стороны, как быть банкам с базовой лицензией? K банку, находящемуся на грани банкротства, могут быть применены санационные меры (меры по оздоровлению).

Если рассматривать банковский сектор с точки зрения активов, то можно получить следующие результаты (Рис. 3).

Из данных Рисунка 3 следует, что 60,3\% (58251 837 млн. руб.) всех активов банковской системы РФ приходится на первые пять крупнейших банков, около 22,62\% (21850 821 млн. руб.) приходится на банки с 6 по 20, и всего лишь 17,07\% (16478 491 млн. руб.) на все остальные банки. Самыми надежными банками по активам на 1 января 2020 года стали Сбербанк России, ВТБ, Газпромбанк, Альфа - Банк и Национальный Клиринговый Центр (Таблица 2).

Современному банковскому сектору России свойственна значительная территориальная

Таблица 1. Отличия банков с базовой лицензией от банков с универсальной лицензией [6]

\begin{tabular}{|c|c|c|}
\hline \multicolumn{3}{|c|}{ Отличия } \\
\hline & $\begin{array}{c}\text { Банки } \\
\text { с базовой лицензией }\end{array}$ & $\begin{array}{c}\text { Банки } \\
\text { с универсальной лицензией }\end{array}$ \\
\hline Капитал & Не должен быть менее 300 млн. руб. & Не должен быть менее 1 млрд. руб. \\
\hline $\begin{array}{l}\text { Требования со } \\
\text { стороны ЦБ РФ }\end{array}$ & Меньше & Больше \\
\hline Полномочия & $\begin{array}{c}\text { Могут осуществлять все банковские опе- } \\
\text { рации, за исключением тех, что касаются } \\
\text { работы с иностранными клиентами. В част- } \\
\text { ности, не имеют права открывать счета в } \\
\text { зарубежных банках, кроме как для участия } \\
\text { в иностранной платежной системе. }\end{array}$ & Все банковские операции \\
\hline
\end{tabular}

1.01.20

1.01.19

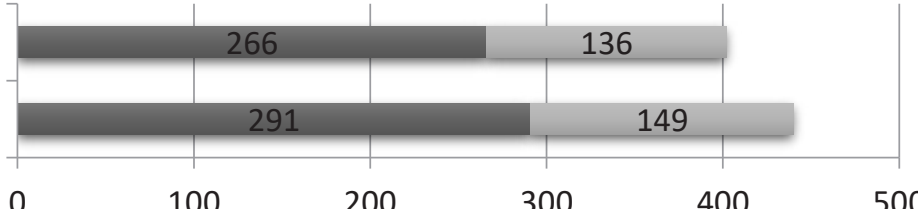

С универсальной лицензией

С базовой лицензией

0

100

300

400

500

Puc. 2. Сравнение количества банков по виду лицензии в 2019-2020 гг. (в ед.) 


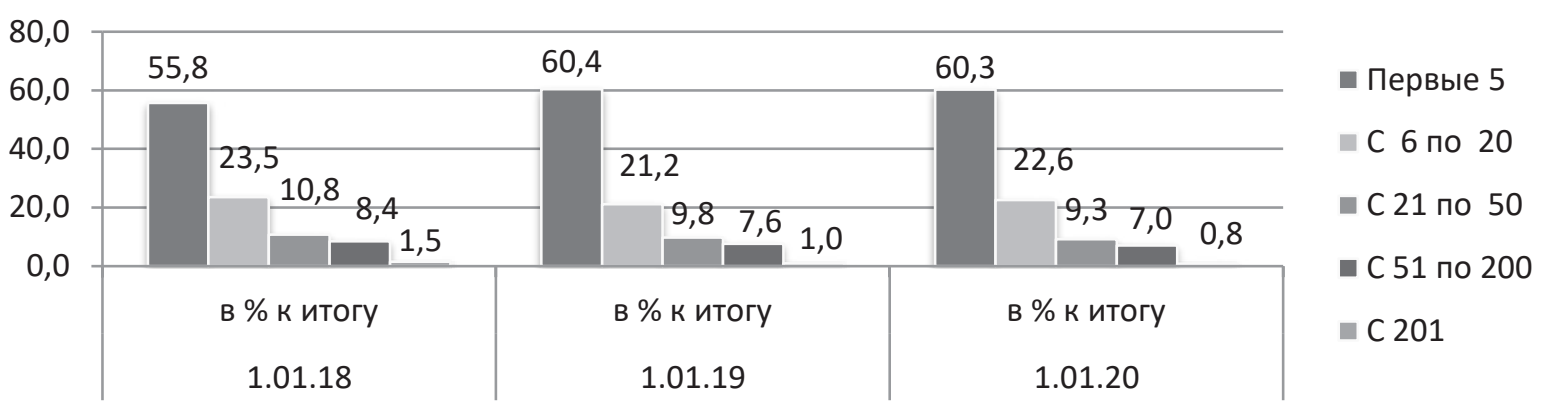

Puc. 3. Распределение кредитных организаций по величине активов в 2018-2020 гг. (в \%) [12]

Таблица 2. Рейтинг десяти ведущих банков России по активам на 1 января 2020 года (млн. руб.) [12]

\begin{tabular}{|c|l|c|c|l|c|}
\hline Место Банк & \multicolumn{1}{|c|}{$\begin{array}{c}\text { Активы, } \\
\text { млн. руб. }\end{array}$} & Место & \multicolumn{1}{|c|}{ Банкивы, } \\
млн. руб.
\end{tabular}

централизация, причем, со временем она все усиливается.

Если 1 января 2018 года в Центральном федеральном округе было зарегистрировано 56,9\% всех кредитных организаций, то 1 января 2020 года данный показатель составил уже 57,2\% (отметим, что за 100\% берется количество действующих КО) (Рис. 4). В частности, в Москве и Московской области на 1 января 2020 года было зарегистрировано 232 кредитные организации, что составило 52,5\% от всех действующих кредитных организаций в стране.

Из этого следует, что банки с большой величиной активов вместе со своими многочисленными структурными подразделениями, чуть ли не все, размещены в Центральном федеральном округе. Такое неравномерное распределение, тоже негативно сказывается на состоянии банковской системы, и, не способствует удовлетворению потребностей социально - экономического развития регионов.

Второй стадией банковского надзора является дистанционный (документарный) надзор. Под ним понимается проверка форм отчетности, которые предоставляет кредитная организация в ЦБ РФ, об осуществляемой деятельности за определенный период времени. В 2017 году лицензии были отозваны у 51 кредитной организации, в 5 случаях причиной послужило установление факта существенной недостоверности отчетных данных. В 2018 году таких случаев было только 5, при общем количестве отзывов - 60 .

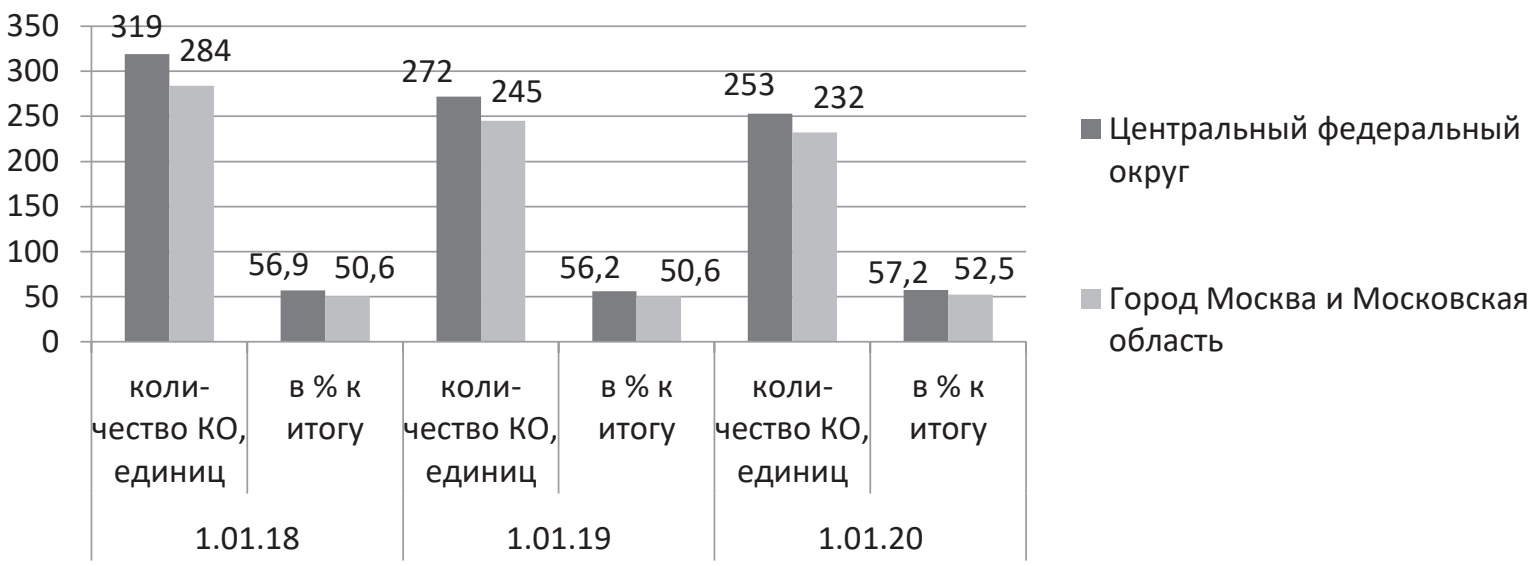

Puc. 4. Динамика количества действующих кредитных организаций по центральному федеральному округу (в ед. и\%) [12] 
Если же все данные в отчетах достоверны, и все заполнено в срок, то документарный надзор может быть использован как мера раннего предупреждения сбоев в деятельности, как самой кредитной организации, так и деятельности всей банковской системы в будущем.

Еще одним элементом системы банковского контроля и надзора является инспектирование на местах, т.е. контроль над достоверностью предоставляемых данных. Такой вид надзора предполагает оценку общего состояния банков или отдельных направлений их деятельности.

При выявлении определенных проблем в деятельности кредитных организаций, происходит изучение особенностей их появления, а также возможностей КО самостоятельно устранить угрозу. В дальнейшем анализируется возможность данного банка обеспечивать принятые на себя обязательства перед вкладчиками. Если такое не представляется возможным, то ЦБ РФ отзывает лицензии и, соответственно, происходит ликвидация банка.

На сегодняшний день, многие банки ликвидируются добровольно, принудительно Центральным Банком РФ (одна из мер, которую Банк России может принять для повышения уровня надежности банковской системы РФ) или в связи с наступлением банкротства (неспособностью КО удовлетворить требования кредиторов или обязанности по уплате обязательных платежей).

Количество обанкротившихся КО на 1 января 2020 г. составило 349, т.е., иными словами, 349 банков не смогли расплатиться по своим обязательствам, что также является показателем ненадежности банковской системы РФ (Рис. 5).

В целях предупреждения банкротства, могут осуществляться меры по его недопущению, как самими собственниками банков, так и с участием Банка России или государственной корпорации «Агентство по страхованию вкладов» $(\Gamma \mathrm{K} « \mathrm{ABC})$.

Суть процесса санации сводится к тому, что проблемному банку находят другого владельца, который устранит все угрозы. Новым владельцем может стать более крупный коммерческий банк или сам Банк России. Банк - санатор получает льготный кредит, который тратит на оздоровление проблемного банка. Такой процесс лечения долгий - он рассчитан на 10-15 лет.

При принятии решения о санации банка с участием Банка России прежде учитывается системная (региональная) значимость этого банка и возможные последствия в случае аннулирования его лицензии.

С 2017 года начал работать новый механизм санации - прямое участие в капитале. Он предусматривает оказание ЦБ РФ финансовой помощи КО, в том числе и с помощью приобретения акций (долей в уставном капитале), предоставления кредитов, размещения депозитов за счет денежных средств составляющих Фонд консолидации банковского сектора, имущество которого обособлено от имущества ЦБ РФ. Преимущества данного механизма оздоровления: происходит сокращение государственных расходов, значительно сокращаются и сроки оздоровления КО, создаются равные конкурентные условия для деятельности КО, повышается эффективность контроля за использованием государственных средств.

В некоторых случаях ЦБ РФ аннулирует лицензии у не обанкротившихся кредитных организаций, но уже в связи с иными причинами, рассмотренными ниже. Это является еще одной мерой по повышению надежности банковской системы РФ, поскольку, таким образом, Банк России очищает банковский сектор от недобросовестных КО.

По данным Рис. 5 на 1 января 2020 года принудительной ликвидации были подвержены 33 кредитные организации. Причины отзыва лицензии здесь самые разные: установление недостоверности сведений, по которым была выдана лицензия; задержка в предоставлении отчетной информации (более чем на 15 дней); неисполнение федеральных законов, регулирующих банковскую деятельность, а также нормативных ак-

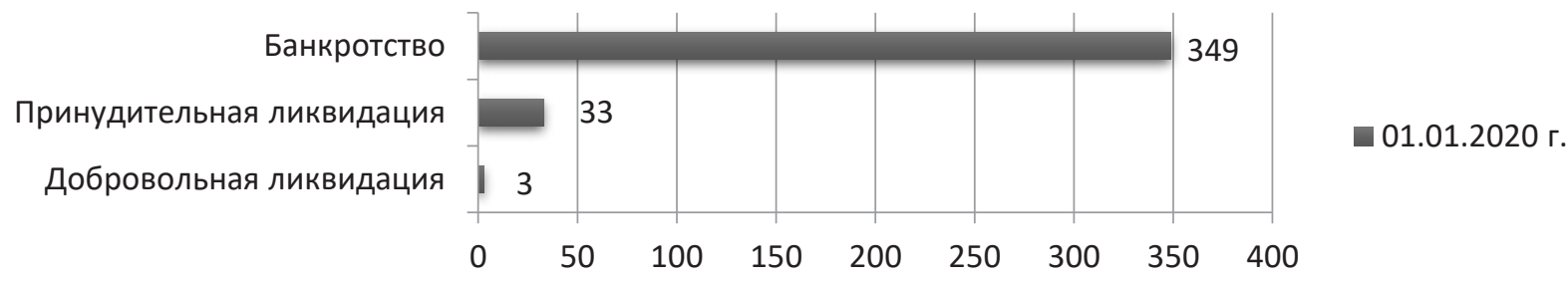

Puc. 5. Количество кредитных организаций в стадии ликвидации (в ед.) [4] 
тов Банка России и т.д. [8] Все основания отзыва лицензии законодательно закреплены в статье 20 Ф3 № 395-1 «О банках и банковской деятельности».

Подводя итоги всего вышеизложенного, приведем следующие основные выводы:

1. Анализ состояния банковского сектора показал, что существуют определенные проблемы в его развитии, затрагивающие и уровень надежности:

- Неравномерность распределения банков по стране;

- Количество банков, которое уменьшилось;

- Соотношение банков с универсальной и базовой лицензиями;

- Большое количество обанкротившихся банков;

- Много случаев принудительной ликвидации банков ЦБ РФ.

2. Надежность банковской системы тесно связана с такой функцией ЦБ РФ как надзор и контроль. Данные, получаемые от контрольной деятельности Банка России, позволяют своевременно выявить угрозы стабильности и надежности банковской системы.

3. Основываясь на данных, полученных от документарного надзора и инспектирования, Банк России, может принять необходимые меры для устранения этих проблем, например, при угрозе банкротства, может санировать банк (причем с 2017 года ЦБ РФ ввел еще один механизм оздоровления банков) или же, например, ЦБ РФ может отозвать лицензию «провинившегося» банка.

Таким образом, Банк России - важнейший финансовый институт государственного регулирования экономики, который играет ключевую роль как в системе регулирования и надзора за деятельностью кредитных организаций, так и банковской системы в целом. В частности, деятельность ЦБ РФ позволяет повысить уровень надежности банковской системы РФ.

\section{Библиографический список}

1. Аликаева М.В., Дзагоева М. Р., Оборин М. С., Ксанаева М.Б., Бжихатлов С. Х. Современные тенденции формирования российского рынка банковских услуг // Вестник Северо-Осетинского государственного университета имени К. Л. Хетагурова. 2018. № 4. С. 77-84.

2. Бобошко Н.М., Проява С.М., Тиникашвили Т.Ш., Куцури Г.Н., Лебединская О.Г., Тимофеев А. Г. Финансовокредитная система / Москва, 2021. (Второе издание, переработанное и дополненное).

3. Гагиева О.Х., Тадтаева Н. В., Чшиева З.Г. Институциональные аспекты развития банковской отрасли // Экономика и предпринимательство. 2016. № 11-4 (76). С. 77-81.

4. Данильянц Г.Г., Позмогов А.И. Факторы оздоровления российской банковской системы // Экономика и предпринимательство. 2020. № 6 (119). С. 144-147.

5. Козаева О.Т., Хатагов М.И. Проблемы потребительского кредитования в России и перспективы развития // Экономика и управление: проблемы, решения. 2018. Т. 5. № 12. С. 105-110.

6. Кулумбекова Т.Е., КулумбеговаЛ.В. Депозитный потенциал банковской системы России: анализ и оценка / В сборнике: Состояние и перспективы развития экономики региона. Сборник научных статей Второго Владикавказского экономического форума, посвященного 115-летию Н.А. Цаголова и 50-летию экономического факультета СОГУ. Под редакцией А. У. Огоева. 2020. С. 132-138.

7. Кулумбекова Т.Е., Токаева Т.И., Тибилова 3.В. Кредитные ресурсы банковской системы: формирование, ограничения, риски и показатели использования // Северо-Осетинский государственный университет имени К. Л. Хетагурова. Владикавказ, 2019.

8. Сугарова И.В., Алборова А.Э. Анализ банковской системы России на основе количественных и качественных показателей // Экономика и предпринимательство. 2016. № 11-4 (76). С. 141-146.

9. Тадтаева В.В., Чомаева В.М. Потребительское кредитование в реалиях российской экономики // Экономика и предпринимательство. 2016. № 11-4 (76). С. 563-566.

10. Токаев Н.Х., Тезиева М.В., Дзагоев А.Х. Модификации в банковской системе РФ и проблематика отзывов лицензий банков // Экономика и предпринимательство. 2016. № 11-4 (76). С. 627-629.

11. Токаева С.К., Гуриева Л.К., ТуаеваЛ.А., Хубаев Т.А., Дзагоева М.Р., Тогузова И.З., ДоеваФ.Н., Тавасиева З.Р . Управление социально-экономическими системами / Учебное пособие / Москва, 2020. Сер. 76 Высшее образование (1-е изд.)

12. Рейтинги банков [Электронный ресурс] // www.banki.ru - Режим доступа: https://www.banki.ru/banks / ratings/ - свободный 